\title{
O que a Revista Brasileira de Oftalmologia busca para a Oftalmologia brasileira
}

A Revista Brasileira de Oftalmologia (RBO) ISSN 0034-7280 é um periódico bimestral da Sociedade Brasileira de Oftalmologia, que é publicado ininterruptamente desde sua criado conhecimento científico da oftalmologia brasileira, bem como de suas áreas afins.

Representa grande parte da história da publicação brasileira em oftalmologia e já publicou 3.317 artigos de pesquisa, dos quais 1.660 estão disponíveis na base de dados da Literatura LatinoAmericana em Ciências da Saúde (Lilacs), representando a segunda maior revista da América Latina em número de artigos publicados.

Segundo dados da SciELO, a Revista Brasileira de Oftalmologia é a oitava revista mais citada nesta base por revista da área, juntamente com citações de revistas de grande impacto internacional, o que demonstra relevância, competência científica e reconhecimento do valor científico de seus artigos para as pesquisas na oftalmologia brasileira.

A RBO oferece uma tiragem de 5.000 exemplares impressos para oftalmologistas, bibliotecas nacionais e internacionais e disponibiliza eletronicamente seus artigos desde 2004.

A Revista Brasileira de Oftalmologia mantém uma política editorial para aprovação dos artigos para publicação baseada na metodologia de "peer review" (revisão por pares). Todos os artigos submetidos à RBO, após análise pelo corpo editorial, são encaminhados para avaliação por dois ou mais revisores. As sugestões dos revisores são reencaminhadas_aos autores para fazerem suas adequações ou justificativas. $\mathrm{O}$ anonimato é assegurado em todo o processo de revisão.

Para garantir a qualidade editorial das publicações, a Revista é submetida a um revisor de idioma e a um bibliotecário especializado, que faz toda a revisão técnica dos artigos, bem como a análise e correção das citações e referências bibliográficas. Conforme consta nas instruções aos autores, a RBO adota o padrão Vancouver em suas citações e referências, o mesmo adotado por todas as revistas de padrão internacional.

A RBO apresenta ampla abrangência e representatividade nacional quanto aos autores de artigos, membros do corpo editorial e conselho científico, com afiliação institucional em todos os fascículos e adequada percentagem de artigos originais publicados por ano.

Recentemente, atendendo a todos os requisitos estabelecidos pela Diretoria da CAPES (Coordenação de Aperfeiçoamento de Pessoal de Nível Superior) a RBO foi incluída no Portal de Periódicos da Capes (www.periodicos.capes.gov.br). Desta forma, a versão on-line disponibilizada ao leitor, mostra a capa, sumário e artigos completos da revista.

Embora, objetivamente a qualidade de uma revista se expresse pelo seu conteúdo, todos os indexadores e reguladores de publicação científica exigem a normalização como um dos critérios para o registro e inclusão em suas bases de dados. Estamos buscando estar em conformidade com os preceitos e normas atuais de qualidade editorial para preservar e elevar, ainda mais, a credibilidade da RBO. Assim, uma boa notícia é que a RBO foi aprovada na primeira etapa do processo de 
seleção e avaliação de periódicos da coleção SciELO Brasil, após a qual será submetida à análise de mérito científico.

A indexação da RBO nos bancos de dados, mais do que alterar o seu status junto às agencias de financiamento à pesquisa do governo brasileiro, irá contribuir para ampliar o potencial de publicação e de citações das pesquisas e autores brasileiros.

Riuitiro Yamane

Editor Chefe da Revista Brasileira de Oftalmologia Professor Titular de Oftalmologia da Universidade do Estado do Rio de Janeiro

Edna Terezinha Rother Bibliotecária, Editora Técnica de Publicações Científicas

Arlindo José Freire Portes Professor Adjunto em Oftalmologia e Saúde da Família da Universidade Estácio de Sá Coordenador do Curso de Educação Médica Continuada da SBO e Co-editor da RBO 